\title{
EFFECT OF PERCUSSION AND POSTURAL DRAINAGE POSITIONS ON CARDIOVASCULARAND RESPIRATORY PARAMETERS
}

\author{
Journal website at; \\ http://mrtbjournal.org/index.php/njmr/issue/current/showToc \\ AT ONIGBINDE, RA ADEDOYIN, OO ORIJAJOGUN, OKULAJA IYABO* \\ Medical Rehabilitation Departnent, Faculty of Basic Medical Sciences, College of Health Sciences, \\ Obafemi Awolowo University,Ile-Ife, Osun State. \\ * Physiotherapy Department, State Hospital, Abeokuta, Ogun State. \\ correspondence \\ OnigbindeAT \\ ayotesonigbinde@yahoo.co.uk
}

\begin{abstract}
SUMMARY
Background of the study: There are different drainage positions for different lobes of the lungs but most studies on the effect of postural drainage and percussion on cardiovascular and cardiorespiratory are old and also inconclusive.

Aims: The primary aim of this study was to determine the effect of postural drainage positions and percussion in prone lying with foot of bed raised to $45 \mathrm{~cm}$ and right side lying with 45 degree turn on to the face on cardiovascular and cardiorespiratory parameters such as systolic blood pressure (SBP), diastolic blood pressure (DBP), heart rate (HR) and respiratory rate (RR).

Method: Forty subjects (20 males and females each) participated in the study and they were randomly assigned to 4 groups with 10 participants in each group. The cardiovascular and cardiorespiratory parameters were measured at sitting (pre-positioning), mid and postpositioning after 15 minutes. The data was analysed using descriptive and inferential statistic.

Results: The results showed that percussion significantly decreased the systolic blood pressure $(F=3.15 ; p<0.05)$ while the respiratory rate was increased significantly $(\mathrm{F}=$ $5.40 ; \mathrm{p}<0.05)$ when the subjects were in prone lying position. The result also showed that the systolic blood pressure and the respiratory rate increased significantly $(F=1.26 ; p<0.05)$ and $(F=7.18 ; p<0.05)$ respectively when the subjects changed from sitting to prone lying positions. Conclusion: This result showed that some postural drainage positions and percussion affects the systolic blood pressure and the respiratory rate
\end{abstract}

KEY WORDS: Postural drainage, Percussion, Blood pressure, Respiratory rate

\section{INTRODUCTION}

Postural drainage is a chest physical therapy procedure that uses the force of gravity to assist in effectively draining secretion from the lungs into the central airways where they can either be coughed or suctioned out (AARC, 2004). It is indicated when there is difficulty with secretion clearance with expectorated sputum production greater than $25-30 \mathrm{ml} /$ day (Faling; 1986). Postural drainage relates to the positioning of a person to drain secretion from particular area of the lungs. The specific position involved in postural drainage allows different lobes to be drained. The segmental bronchus being drained is placed in the most vertical position for gravity to have its effect (Rhonda, 2004). The procedure will help to reduce pulmonary infection by removing the secretion from the lungs and consequently contributing to the overall health care of the patient (Rhonda, 2004).

Postural drainage is indicated in chronic obstructive pulmonary diseases like chronic bronchitis, brochiectasis, cystic fibrosis and asthma. Patients who are likely to aspirate mucous secretion because of disease such as cerebral palsy or muscular dystrophy also benefits from postural drainage (AARC, 2004). Similarly, it is indicated in individuals who are bedridden, confined to wheelchair and who cannot breathe deeply because of post-operative pain (AARC, 2004). Previous investigators had investigated the effect of posture and positioning during postural drainage on the cardiovascular system (Foley 1971; Barrel and Abass, 1978). But they reported contradictory findings. These investigators limited the positions assumed to very few drainage positions out of the 10 possible positions (Gaskell \& Webber, 1977), although, Green (2003) identified 6 possible postural drainage positions.

Respiratory diseases are increasing in the developing countries despite the improved medical management. The physical management of these conditions will therefore remain a challenge to Physiotherapists, because critically ill paticnts verging on cardiovascular instability llay require postural drainage. The effect of this treatment on the cardiovascular and cardiorespiratory does not seem 
well defined (Arigbabuwo and Adedoyin, 2002). Similarly, most of these contradictory studies were old and needed to be updated. The primary aim of this study was to determine the effect of postural drainage and percussion on cardiovascular and cardiorespiratory parameters such as blood pressure, heart rate and respiratory rate.

\section{MATERIALSAND METHOD}

A total of forty subjects (20 males and 20 females) participated in this study. Participants were all undergraduate students of Obafemi Awolowo University, Ile-Ife, Nigeria. They were apparently healthy, with no history of cardiovascular, cardio respiratory and neurogenic disease. All the participants signed a consent form to express their willingness to participate in this study and the institutions' ethic committee approved the protocol. This study was carried out in the electrotherapy laboratory of the department of Medical Rehabilitation, College of Health Sciences, Obafemi Awolowo University, Ile-Ife, Osun State, Nigeria.

\section{Instrumentation}

A digital sphygmomanometer (OMRON Healthcare Inc HEM-712C , China) was used to measure the blood pressure and pulse rate in millimetres of mercury $(\mathrm{mmHg}$ ) and beat $\backslash$ minute respectively. A bathroom weighing scale (Hanson Company, Japan) was used to measure the weights of subjects in kilogram (kg). Both the digital and bathroom weighing scale were found to be highly reliable ( $r=0.95$ and 0.97 respectively). Others are Stadiometer ard Stopwatch to measure height and respiratory rate respectively. Also, a Rehabilitation step board was used as tipping to raise the foot of the plinth by $45 \mathrm{~cm}$.

\section{Procedure}

The forty subjects used were assigned randomly into four groups using alternate randomization in order of how they reported (i.e. groups 1, 2, 3 and 4). Each group consisted of 10 subjects ( 5 males and females each). The subjects' age, height and weight were measured and recorded.

Group 1 and 2 subjects were placed in prone lying position; with the foot of bed raised to $45 \mathrm{~cm}$ (to drain the left posterior bronchus of the upper lobe). While Group 1 participants were percussed, Group 2 did not receive percussion. Group 3 and 4 were positioned in right side lying with $45^{\circ}$ turn on to the face and pads were arranged to lift the shoulder $30 \mathrm{~cm}$ (Gaskel and Weber, 1977) from the bed (to drain the post basal bronchus of the lower lobe). Group 3 subjects were percussed while Group 4 did not receive percussion.

Prior to the measurement of parameters, each participant was allowed to rest for five minutes in sitting position (pre-treatment measurement). Subsequently, the blood pressure, heart rate, and respiratory rate were measured in the sitting position. Subjects were then placed in their various postural drainage positions (mid-treatment measurement) and the second measurements of blood pressure, pulse rate and respiratory rate were laken immediately after positioning the subjects. Subjects in group 1 and 3 received percussion in their positions for 10 minutes each (intermittently).

All the subjects maintained their postural drainage positions for 15 minutes each. The third measurements of blood pressure, pulse rate and respiratory rate were taken at the end of the 15 minutes in sitting position (posttreatment measurement).

\section{DATAANALYSIS}

Both descriptive and inferential statistics were used to analyse the data obtained. The descriptive analysis used included mean and standard deviation while inferential statistics- Analysis of variance (ANOVA) was used to determine if there was a significant difference within each group when they changed positions. ANOVA was also used to compare the physical characteristics of the 4 group participants.

\section{RESULTS}

The results of the ANOVA showed that the mean age, height and weight of all the subjects were comparable as there were no significant differences in all the anthropometric parameters across the groups (Table 1).

Table 1: Comparison of the Anthropometric Parameters, Cardiovascular and Respiratory Parameters (Postpositioing) of the 4 Groups

\begin{tabular}{|c|c|c|c|c|c|}
\hline \multicolumn{2}{|c|}{ Groups } & Mean & SD & $\mathbf{F}$ & Sig \\
\hline \multirow[t]{4}{*}{ AGE } & 1 & 23.7 & 2.4 & & \\
\hline & 2 & 23.5 & 3.7 & & \\
\hline & 3 & 25.3 & 4.5 & & \\
\hline & 4 & 23.3 & 2.3 & 0.72 & 0.54 \\
\hline \multirow[t]{4}{*}{$\mathrm{HT}$} & 1 & 1.7 & 0.1 & & \\
\hline & 2 & 1.6 & 0.1 & & \\
\hline & 3 & 1.7 & 0.1 & & \\
\hline & 4 & 1.7 & 0.1 & 2.72 & 0.55 \\
\hline \multirow[t]{4}{*}{ WT } & 1 & 57.2 & 8.3 & & \\
\hline & 2 & 54.1 & 7.3 & & \\
\hline & 3 & 63.8 & 7.2 & & \\
\hline & 4 & 58.8 & 6.4 & 2.29 & 0.09 \\
\hline \multicolumn{6}{|l|}{ bhh } \\
\hline \multirow[t]{4}{*}{ SYST.BP } & 1 & 105.0 & 4.1 & & \\
\hline & 2 & 112.7 & 8.7 & & \\
\hline & 3 & 105.0 & 8.1 & & \\
\hline & 4 & 103.8 & 10.4 & 3.15 & 0.03 \\
\hline \multirow[t]{4}{*}{ DIAST. BP } & 1 & 65.8 & 7.9 & & \\
\hline & 2 & 69.3 & 7.2 & & \\
\hline & 3 & 65.3 & 7.4 & & \\
\hline & 4 & 63.1 & 7.7 & $1 . .29$ & 2.30 \\
\hline \multicolumn{6}{|l|}{ HEART } \\
\hline \multirow[t]{4}{*}{ RATE } & 1 & 70.7 & 8.9 & & \\
\hline & 2 & 69.3 & 9.9 & & \\
\hline & 3 & 65.0 & 7.7 & & \\
\hline & 4 & 70.1 & 9.0 & 0.84 & 0.48 \\
\hline \multirow[t]{4}{*}{ RESP.RATE } & 1 & 25.4 & 3.8 & & \\
\hline & 2 & 22.6 & 4.1 & & \\
\hline & 3 & 19.6 & 3.1 & & \\
\hline & 4 & 19.8 & 3.8 & 5.40 & 0.004 \\
\hline
\end{tabular}


The results of the ANOVA used to compare the mean values of the cardiovascular and cardio respiratory parameters between the 4 groups to know the effect of percussion at the end of the treatment session showed a significant difference in the $\operatorname{SBP}(F=3.15 ; \mathrm{p}<0.05)$ and the respiratory rate, $R R(F=5.40, p<0.01)$ on percussion. However, the mean DBP and HR showed no significant differences $(F=-1.30 ; p>0.05)$ and $(F=0.84 ; p, 0.05)$, respectively (Table 1 ). The results of the pos-hoc analysis showed that the mean systolic blood pressure of group 2 participants who did not receive percussion was significantly higher $(\mathrm{p}<0.05)$ compared to group 1 participants who were percussed.

The results (Table 2) showed a significant increase in the systolic blood pressure (SBP) between the 3 positions (pre- treatment, mid-treatment and posttreatment) after 15 minutes for Group 1 subjects, $(F=5.52$; $\mathrm{p}<0.05)$ but there was no significant difference in the diastolic blood pressure, DBP $(F=1.26 ; p>0.05)$ and heart rate, HR ( $F=0.12 ; p>0.05)$. There was also a significant increase in the mean value of the respiratory rate $(R R)$ in the 3 positions $(F=7.18 ; \mathrm{p} \ll 0.05)$. There were no significant differences in the SBP $(F=0.13 ; p>0.05), \operatorname{DBP}(F=0.28 ; \mathrm{p}$ > $0.05)$ and $H R(F=0.29, p>0.05)$ for the group 2 participants who were not percussed. $(F=4.15 ; \mathrm{p}<0.05)$.

Similarly, this study found no significant difference in the mean $\operatorname{SBP}(F=1.13 ; p>0.05), \operatorname{DBP}(F=2.20 ; p>0.05)$, and $H R(F=0.60 ; p>0.05)$ for group 3 (Table 3$)$. The mean

Table 2: The Result SOF the ANOVA comparing the Pre,Mid and Post Positions in Group 1 and 2.

\begin{tabular}{lllllll}
\hline & & Mean & SD & F & P \\
\cline { 1 - 2 } Group 1 (Percussed) & & & & \\
Systolic BP & Pre & 100.6 & 8.2 & & \\
& Mid & 110.0 & 6.1 & & \\
Diastolic BP & Post & 105.0 & 4.5 & 5.52 & 0.01 \\
& Pre & 61.4 & 5.9 & & \\
& Mid & 64.7 & 5.3 & & \\
Heart Rate & Post & 65.8 & 7.9 & 1.26 & 0.3 \\
& Pre & 72.5 & 9.1 & & \\
& Mid & 72.2 & 8.0 & & \\
Resp. Rate & Pos & 70.7 & 8.9 & 0.12 & 0.88 \\
& Pre & 20.6 & 2.8 & & \\
& Mid & 25.0 & 2.7 & & \\
Group 2 (Without & Pest & 25.4 & 3.8 & 7.18 & 0.03 \\
Systolic BP & Pre & 110.5 & 11.0 & & \\
& Mid & 112.5 & 12.0 & & \\
Diastolic BP & Post & 112.7 & 8.7 & 0.13 & 0.88 \\
& Pre & 67.3 & 8.4 & & \\
& Mid & 67.2 & 7.2 & & \\
\multirow{5}{*}{ Heart Rate } & Post & 69.3 & 5.2 & 0.28 & 0.76 \\
& Pre & 71.4 & 11.6 & & \\
Resp. Rate & Mid & 72.8 & 9.6 & & \\
& Post & 69.3 & 9.9 & 0.29 & 0.75 \\
& Pre & 19.7 & 2.5 & & \\
& Mid & 25.0 & 5.3 & & \\
& Post & 22.6 & 4.1 & 4.15 & 0.03 \\
\hline
\end{tabular}

RR however showed a significant increase $(\mathrm{F}=3.56 \mathrm{p}$, $0.05)$. The result also showed no significant differences in the mean $\mathrm{SBP}(\mathrm{F}=0.50 ; \mathrm{p}>0.05), \mathrm{DBP}(\mathrm{F}=1.61 ; \mathrm{p}>0.05)$, HR $(F=0.58 ; p>0.05)$ and the mean $R R(F=2.48 ; p>0.05)$ in the pre, mid and postpositions for group 4 subjects.

Table 3: The Results of the ANOVA comparing the Pre, Mid and Post Positions in Group 3 and 4

\begin{tabular}{lllllll}
\hline & & Mean & S D & F & P \\
\hline Group 3 (Percussed) & & & & \\
Systolic BP & Pre & 111.9 & 8.5 & & \\
& Mid & 109.0 & 10.0 & & \\
& Post & 105.9 & 8.2 & 1.13 & 0.34 \\
Diastolic BP & Pre & 69.5 & 8.2 & & \\
& Mid & 61.9 & 8.6 & & \\
& Post & 65.3 & 7.4 & 2.20 & 0.13 \\
Heart Rate & Pre & 67.5 & 10.2 & & \\
& Mid & 69.2 & 7.7 & & \\
& Post & 65.0 & 7.7 & 0.60 & 0.55 \\
Resp. Rate & Pre & 19.4 & 2.5 & & \\
& Mid & 22.4 & 2.8 & & \\
Group 4 (Without Percussion) & & & \\
Systolic BP & Pre & 100.2 & 14.7 & & \\
& Mid & 105.5 & 10.7 & & \\
& Post & 103.8 & 10.4 & 0.50 & 0.61 \\
Diastolic BP & Pre & 63.8 & 15.8 & & \\
& Mid & 61.5 & 7.2 & & \\
& Post & 63.1 & 7.7 & 1.61 & 0.22 \\
Heart Rate & Pre & 66.3 & 8.0 & & \\
& Mid & 69.6 & 8.8 & & \\
Resp. Rate & Post & 70.0 & 9.0 & 0.58 & 0.57 \\
& Pre & 19.6 & 4.0 & & \\
& Mid & 20.0 & 3.7 & & \\
& Post & 19.8 & 3.8 & 2.48 & 0.10 \\
\hline
\end{tabular}

\section{DISCUSSION}

There is the general speculation that position assumes for postural drainage may affect the cardiovascular and cardiorespiratory system most especially in a diseased state. Previous studies had tried to investigate this assumption but controversies and contradictory reports are the end result. The result of this study revealed that systolic blood pressure significantly increased when the subjects changed position from sitting to prone lying with foot of bed-raised $45 \mathrm{~cm}$. This finding supported previous reports ((Lemarr et al;1983, Klatz et al;1983,Sobush et al;1986,Ballantyne et al;1986,Haskvitz and Hanten;1986)) that change in positions increase blood pressure and heart rate, however, it is contradictory to the findings of White and Mawsdley (1983) and Foley(1971) who reported a significant decrease of the systolic blood pressure (SBP) when subjects change from sitting to prone lying position. Similarly, the result is contradictory to the reports of Haseqawa and Rodboard (1979) who reported no significant difference in systolic blood pressure (SBP), although, this was between standing and prone lying. Also, Arigbabuwo and Adedoyin (2002) reported a 
significant decrease in systolic blood pressure (SBP) when subjects changed from supine lying to side lying. This study also showed no significant difference in the diastolic blood pressure (DBP) when subjects changed position from sitting to prone lying. This is not in line with Arigbabuwo and Adedoyin (2002) who reported a decrease in the DBP when their subjects changed from supine lying to level prone lying. The inconsistencies observed here might be as a result of the different posture adopted in the studies. Foley (1971) and, Arigbabuwo and Adedoyin (2002) used subjects that changed from supine lying to side lying and head down side lying. White and Mawdsley (1983) reported that the cause of the change in cardiovascular parameters when their subjects change position is obscure. The variation in the parameters may be due partially to a decrease in hydrostatic pressure in the brachial artery (Foley, 1971). But Davis et al (2001) observed that loss of general muscle tone, decrease of efficiency of the orthostatic neurovascular reflexes and changes in the vascular resistance and the hydrostatic pressure associated with lying down alter the distribution of blood within the body and may be responsible for the change in the blood pressure. This study also revealed a significant increase in the respiratory rate (RR) when the subjects changed from sitting to prone lying and to right side lying. However, the difference in respiratory rate (RR) could be attributed to the changes in physiological demands associated with changing from one position to another. Also, anxiety and apprehension of assuming an awkward position may trigger off an increase in cardiorespiratory demand.

Similarly, this study revealed that percussion significantly decreased the systolic blood pressure (SBP) when subjects were in prone lying with foot of bed raised $45 \mathrm{~cm}$. This result contradicted the findings of White and Mawdsley (1983) and Arigbabuwo and Adedoyin (2002) who reported that the addition of percussion to level side lying and head down lying did not significantly affect the CV parameters. However, this study supported the findings of Barre and Abass (1978) who reported that pulmonary physical therapy that included percussion had effect on the cardiovascular system when administered to patients within 24 hrs although in a mitral valve surgery. Since some cardiovascular and cardiorespiratory parameters most especially systolic blood pressure and respiratory rate showed significant changes when participants change from sitting to prone lying, foot of bed raised $45 \mathrm{~cm}$, and right side lying positions. Physiotherapists should take extra precautions when treating patients with Cardiovascular and cardiorespiratory disorders, most especially patients who are hypertensive and those that presents with tachypnoea secondary to respiratory/cardiac disorders.

Also, this study revealed a significant decrease in systolic blood pressure when percussion was applied. Physiotherapists and other health workers should have this in mind as a precaution in the use of percussion with normotensive and hypertensive patients. It is important to know the cardiovascular and cardiorespiratory parameters of patients before performing postural drainage with and without percussion. However, the result of this study should be interpreted with caution as normal subjects were used. It is recommended that further studies should be done on the effect of postural drainage and percussion using cardiovascular and cardiorespiratory diseased patients.

\section{REFERENCES}

- AARC - American Association for Respiratory Care (2004): Clinical practical guideline; Respiratory Care. Vol. 36: 1418 $-26$

- Arigbabuwo and Adedoyin (2002): Effect of two selected postural drainage positions and percussion on healthy subjects. A Journal of the Nigeria Society of Physiotherapy 14(1): $9-15$.

- Ballantyne BI, Reser MD, Lorenz GW and Smith GL (1986): Inversion traction: Effect on spinal column; heart rate and blood pressure. Physical Therapy 7(5): $254-60$.

- Barrel SE and Abass HM (1978): Monitoring during Physiotherapy after open heart surgery: Physiotherapy 1978; 64(90): $272-3$.

- Davis K, Johanningman J, Cambell K and Branson R (2001): The acute effects of body position strategies and respiratory therapy in paralyzed patients with acute lung injury. An article submitted to PubMed Central.

- Failing LJ (1986): Pulmonary rehabilitation; physical modalities; clinical chest med. 7(4): pgs. 599-618.

- Foley MF (1971): Variations in blood pressure in the lateral recumbent position, Nurse Res 20: 64-9

- Gaskell DV and Webber (1977): A textbook of Brompton hospital guide to chest Physiotherapy. $5^{\text {th }}$ Edition. Blackwell Scientific, Osuey Mead, Oxford England.

- Green GC (2003): Why carry out mucus clearance therapy? An overview of airway clearance techniques.

- Haskivtz EM and Hanten WP (1986): Blood pressure response to inversion. Physical Therapy 66(9): $1361-64$.

- Hasegawa M and Rodboard S (1979): Effect of posture on arterial pressure limiting of the arterial sound and pulse wave velocity in the extremities. Cardiology 64: $122-32$.

- Klatz RM, Goldman RM, Pinchuk BG, Nelson KE and Tarr RS (1983); The effect of gravity inversion procedures on systemic blood pressure. Joumal of American Osteopath Association 82: 852 - 57

- Lemar JO, Golding LA and Cretian KD (1983): Cardiorespiratory response to inversion. The Physician and Sports Medicine 11: 51 - 57 
- Rheault W, Derleth M, Casey M, Czarnik C, Kamad and Nagel G (1985): Efects of an inverted position on blood pressure, pulse rate and deep tendon reflexes of healthy young adults. Physical Therapy 65(9).

- Rhonda Vugsdal-Krenz (2004): Overview of always clearance technique.
- Sobush DC, Nosse LJ and Davis AS (1986): Influence of aerobic fitness on cardiovascular response during slow headdown tilting. Physical Therapy 66(4): $524-30$.

- White DJ and Mawdsley RA (1983): Effect of sclected bronchial drainage position and percussion on blood pressure of healthy human subjects. Physical Therapy, 63(3): 325 330. 